A NEW JOURNAL

\title{
Law and Philosophy
}

An International Journal for Jurisprudence and Legal Philosophy

Edited by

ALAN MABE

Associate Professor and Chair, Department of Philosophy, The Florida State University, Tallahassee, U.S.A.

Law and Philosophy will be a forum for work in philosophy and law which is of common interest to members of the two disciplines. It will be open to all approaches in both fields and to work in any of the major legal traditions - common law, civil law, or the socialist tradition. The editors encourage papers which exhibit philosophical reflection on the law informed by a knowledge of the law, and legal analysis in. formed by philosophical methods and principles.

A distinguished editorial board has been carefully chosen and its composition reflects a concern for balance between legal and philo. sophical perspectives. While each issue will be comprised mainly of articles of a substantial nature, notes and discussions will also be accommodated. Two regular features will be an extended review section and a book note section. Recent important works in jurisprudence and legal philosophy will be treated to an extended review. The book note section will contain annotated bibliographical material on relevant publications.

Contents of Vol. 1 No. 1

Character, Purpose and Criminal Responsibility: Michael D. Bayles. Understanding Judicial Discretion: Barry Hoffmaster. Toward a Theory of Punishment: Alan H. Goldman. Sentencing: Must Justice be EvenHanded?: Michael Davis. Foundation and Safeguard of Human Rights: Ch. Perelman. Illegal Behaviour: Richard Foley. Book Review. Review of Literature.

\section{Subscription Information}

1982, volume 1 (three issues).

Private rate

Dfl. 55, - / US \$ $22.00^{*}$ including postage and handling

Institutional rate

Dfl. 153,- / US \$ 61.50* including postage and handling

"Dollar prices are subject to fluctuations in the exchange rate.

SAMPLE COPIES NOW AVAILABLE

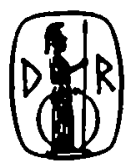

D. Reidel Publishing Company

P. O. Box 17, 3300 AA Dordrecht, The Netherlands 190 Old Derby St., Hingham, MA 02043, U.S.A. 


\section{the}

\section{American}

\section{Society}

\section{THE SOCIETY}

The American Society of Law \& Medicine is a national association designed to serve as a catalyst for interdisciplinary discussion of current, challenging medicolegal issues by concerned members of the health care and legal professions.

\section{MEMBERS}

The membership is comprised of more than 2700 attorneys, physicians, nurses, hospital and nursing home administrators, allied health professionals, academicians, and students from every area of the country and abroad. Members receive subscriptions to two timely medicolegal journals, notice of stimulating continuing education workshops and the opportunity to participate in a national network of professionals with similar interests and concerns.

\section{SAGALL LIBRARY OF LAW, MEDICINE AND HEALTH CARE}

The Sagall Library of Law, Medicine and Health Care, housed at the Society headquarters in the Boston University School of Law, contains the most comprehensive collection of medicolegal reference materials available nationwide. The extensive collection includes over 3000 books, 200 serials, and thousands of periodical articles and court decisions. The user has immediate access to pertinent information on a broad spectrum of medicolegal topics. On-site materials are supplemented by the Boston University School of Law Library.

The Society provides members with direct research and bibliographic assistance plus use of the ASLM Photocopy Service whereby photocopies may be ordered of selected articles.

\section{$\overline{\text { PUBLICATIONS }}$}

\section{LAW, MEDICINE \& HEALTH CARE}

LAW, MEDICINE \& HEALTH CARE is published bi-monthly by the American Society of Law \& Medicine. Each issue contains articles by leading practitioners and academics in the medical, nursing, and legal professions, providing the reader with practical information on a wide range of medicolegal topics. 
The Medicolegal Reference Shelf, a special section of LAW, MEDICINE \& HEALTH CARE, consists of an extensive listing of reference materials. Included are annotations of selected court decisions, a meeting calendar, citations to recent medical, legal, nursing, and health care literature, and listings of new book releases.

LAW, MEDICINE \& HEALTH CARE is essential reading for every professional involved in health care or in the representation of those who provide medical care.

\section{THE AMERICAN JOURNAL OF LAW \& MEDICINE}

The AMERICAN JOURNAL OF LAW \& MEDICINE, co-published with the Boston University School of Law on a quarterly basis, adheres to a law review format. As evidence of its multidisciplinary audience, the AMERICAN JOURNAL OF LAW \& MEDICINE has the distinction of being the only legal publication to be indexed by both legal reference works and the medical reference work, Index Medicus.

Each issue contains original scholarly articles written by national authorities in the fields of health care and the law, plus a Student Notes section and annotations on recent legislative actions. The AMERICAN JOURNAL OF LAW \& MEDICINE is an important addition to the professional's health law library.

\section{CONFERENCES}

A principal activity of the Society is the sponsorship of twelve to fifteen continuing education symposiums, per year, on timely medicolegal issues. Conference topics reflect the needs of the members of the Society as well as the current ethical and legal debate in the fields of health care and the law.

Members of the Society are entitled to a reduced registration fee at all Society sponsored conferences.

To receive a Fall Conference Series schedule please write:

A. Edward Doudera, J.D., Executive Director, ASLM,

765 Commonwealth Ave, 16th Floor, Boston, MA 02115 


\section{Society Membership Information}
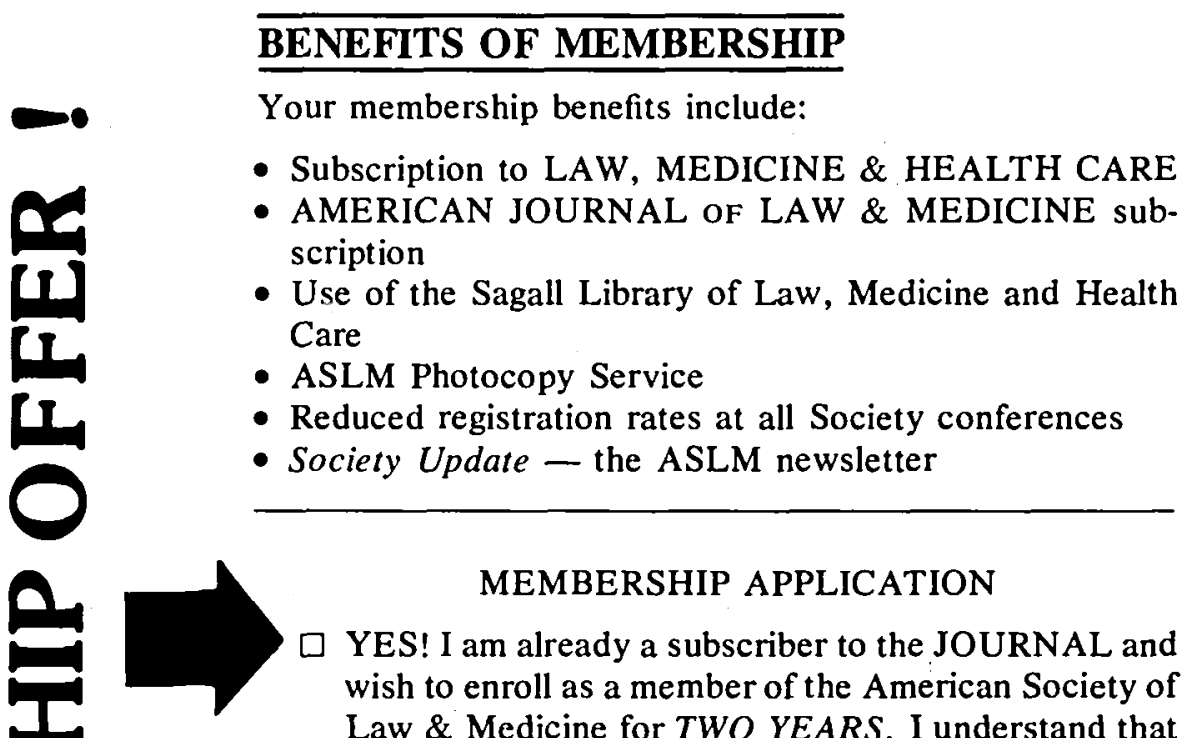

\section{MEMBERSHIP APPLICATION}

YES! I am already a subscriber to the JOURNAL and wish to enroll as a member of the American Society of Law \& Medicine for TWO YEARS. I understand that as a JOURNAL subscriber, if I use this application, a two year membership will cost me ONLY\$100 instead of $\$ 150$. Offer valid until December 31, 1982.

- I am NOT a JOURNAL subscriber but I wish to enroll as a member of the American Society of Law \& Medicine.
One Year: $\$ 75$
Two Years: $\$ 130$
Student: $\$ 30$

SUBSCRIPTION ONLY

$\square$ LAW, MEDICINE \& HEALTH CARE ( 6 issues): $\$ 30$

$\square$ AMERICAN JOURNAL OF LAW \& MEDICINE (4 issues): $\$ 40$

Name:

Title:

Organization:

Address:

City: State: Zip:

Return to: The American Society of Law \& Medicine 765 Commonwealth Ave, 16th Floor, Boston, MA 02215

(617) $262-4990$ 


\section{SUBMISSION OF ARTICLES}

The Editors encourage the submission of manuscripts on a wide range of medicolegal topics for publication in the Journal. Acceptable subjects include health law and policy; legal, ethical, social, and economic aspects if medical practice, education, and research; health-related insurance; and other important or interesting subjects involving the relationship of the life sciences to the social sciences and humanities. The Journal is interdisciplinary. Contributions from specialists in a variety of disciplines are welcomed. All materials should be sent to the Editor-in-Chief, American Journal of Law \& Medicine, Editorial Offices, 765 Commonwealth Avenue, 16th Floor, Boston, Massachusetts 02215.

POLICY ON MULTIPLE SUBMISSION: The Editor-in-Chief receives manuscripts in the understanding that they have not simultaneously been submitted elsewhere for consideration for publication.

GENERAL FORM: Manuscripts should be typewritten on one side of the paper only, with triple spacing and liberal margins. Manuscripts should be submitted in triplicate, i.e., an original and two carbon or Xerox copies. The title of the paper and the author's name and address should be given on a covering sheet.

ABSTRACT: A short abstract (normally not exceeding 200 words) succinctly summarizing the content of the manuscript should accompany the manuscript on a separate sheet. If the paper is accepted, the abstract will be published along with the manuscript.

REFERENCES: Footnotes to sources should be numbered consecutively, and placed on triple spaced pages at the end of the text. All footnotes should conform to $A$ Uniform System of Citation (12th ed.), published and distributed by the Harvard Law Review Association, Gannett House, Cambridge, Massachusetts 02138. Non. lawyers unfamiliar with this system should follow the citation form accepted in their field and the Editors of the JOURNAL will make the appropriate modifications if the paper is published.

ILLUSTRATIONS: Illustrations and tables accompanying manuscripts should be numbered, provided with suitable legends, and marked lightly on the back with the author's name. Authors should indicate on the manuscript the appropriate positions of tables and text figures. Special arrangements must be made with the Editor-in-Chicf for.color plates, claborate tables, half-tone illustrations or extra illustrations, drawings, and photographs.

\section{PUBLICATION LANGUAGE: English.}

SELECTION AND EDITING TIMETABLE: Receipt of manuscript will be acknowledged within one week of receipt. Authors will be notived of the manuscript's acceptance or rejection within one to three months, and accepted manuscripts will be published within three to eight months of acceptance.

PROOFS AND AUTHOR OFFPRINTS: Because of time pressures, printer's proofs of articles accepted for publication will not be made available to authors. Twenty-five offprints of each article, enclosed in Journal covers, will be distributed to the author or divided among the authors if there is more than one. Orders for additional offprints, for which a fee is charged, must be communicated at least one month prior to publication.

RETURN OF MANUSCRIPTS: Upon request of the author and upon receipt of a suitable envelope stamped with adequate postage, the Editor-in-Chief will return to the author the original of any manuscript not accepted for publication. 
